\title{
A Study on the Root Characters of Maize Hybrid Germplasm Lines under Moisture Deficit Stress
}

\author{
Vadlamudi Dinesh Rahul $^{1 *}$, Rajendra Kumar Panda ${ }^{1}$, Devraj Lenka ${ }^{2}$ and G. R. Rout ${ }^{2}$ \\ ${ }^{1}$ Department of Plant Physiology, OUAT,Bhubaneswar-751003, India \\ ${ }^{2}$ Department of Plant breeding and genetics, OUAT. Bhubaneswar-751003, India
}

*Corresponding author

\section{A B S T R A C T}

\section{Keywords}

Root characters, maize, germplasm. Moisture stress

Article Info

Accepted:

22 July 2019

Available Online:

10 August 2019
A field experiment was conducted with twelve hybrid germplasm lines of CYMMIT along with three hybrid checks replicated thrice. Those germplasm lines were evaluated under moisture deficit stress for drought tolerance during the Rabi season 2015. The stress was imposed during the reproductive phase of development and the readings were recorded three times at 55 DAS, 60 DAS, 90 DAS. The parameters recorded were Leaf: Stem ratio, Root length, Root volume, Root: Shoot ratio, Root dry weight, Stem dry weight and leaf dry weights of the plant along with total drymatter, and grain yield. The results obtained from the experiment indicated that the moisture deficit stress during the reproductive growth phase resulted in a drastic decline in the yield by 2 to 3 times than the usual. Root characteristics play an important role in the drought mitigation strategies of maize plants the root length and the root volume results show that a significant increase in root volume in germplasm line Z638-2 from $250 \mathrm{ml}$ to $309 \mathrm{ml}$ resulted in a higher yield of $79.1 \mathrm{~g}$ per plant. The root length also show a similar trend of increase in Z638-2 from $27.50 \mathrm{~cm}$ to $35.53 \mathrm{~cm}$. Root dry weight was observed maximum in Z637-2 which was one of the best yielder.

\section{Introduction}

Drought is an abiotic stress which gained a phenomenal importance across the world with its serious effects on the crop productivity. Maize is the third most important cereal crop in the world and is also a drought sensitive crop. Maize germplasms also have numerous features which enable some accessions to cope with drought stress in better ways (Aslam et al., 2015). Every millimetre of water is responsible for production of $10-16 \mathrm{~kg}$ grains and single maize plant consumes 250 litres of water at maturity (Du Plessis 2003). Being a moisture sensitive crop maize crop is being affected at each and every stage of development. The reproductive growth stage is comparatively more sensitive to drought stress in maize at which it requires $8-9 \mathrm{~mm}$ water per day for a single plant. Thirty days are most crucial regarding water requirement which includes fifteen days before and fifteen days after pollination.

Moisture deficit stress is a serious problem hindering the growth and development of 
maize. Drought stress increases the leaf to stem ratio which is indication of high level of growth retardation in stems than leaves (Hajibabaee et al., 2012). Drought stress reduces the light interception due to the reduced leaf area caused by leaf rolling and also reduced leaf growth which consequently reduce the biomass production. The reduced stomatal activity due to the high temperatures and also plants mechanism to reduce the transpiration rate also reduce the biomass production.

Roots play a crucial role in plant growth and development and are of critical importance for plant because of their capability to detect or sense the of drought stress primarily. Root length, root volume, root density and number of roots are the characteristic structural traits which are disturbed under drought stress and resultantly whole arial plant parts are disturbed (Aslam et al., 2015).

Spatial water uptake and temporal water uptake are functional traits of roots. Root system of maize comprised of axillary and lateral roots. Axillary roots are further comprised of primary, seminal, nodal or crown roots (Cahn et al., 1989). Primary and seminal roots are collectively known as embryonic roots. Seminal roots are permanent and have functional role in growth and development of plant (Navara et al., 1994).

Under mild drought stress roots of maize plant becomes elongated to explore the deeper and distant soil foils for more water uptake whereas, under severe drought stress root length is reduced. Root density, volume and number of roots are reduced under mild and severe drought stress (Nejad et al., 2010). To develop drought-tolerant maize, selection can be performed directly under drought stress, indirectly under well-watered conditions, or simultaneously under both optimal and drought stress conditions (Byrne et al., 1995).

\section{Materials and Methods}

A filed experiment was laid out with twelve hybrid germplasm lines of CYMMIT along with three hybrid checks replicated thrice were evaluated for the moisture stress tolerance during the Rabi' 2015. The moisture stress was imposed by not irrigating the field for a period of one month from a period of 15 days before flowering to the grain filling stage which is one of the most critical stages for water stress in maize plants.

\section{Root length}

The plants are uprooted from the field and brought to the lab as such by tagging and the roots were cleaned under running tap water. Precautions were taken that the roots are not damaged by inundating the plant taken to facilitate easy uprooting. Then the length of the root was measured with the help of a scale obtained in $\mathrm{cm}$.

\section{Root volume}

Due to size factor measurement of maize roots is not possible with the help of a 250 or 500 $\mathrm{ml}$ measuring cylinder. So that a glass beaker was taken which was filled with water up to the brim and then the root was completely immersed in the beaker allowing the water to over flow and then the root was removed from the beaker.

The water over flown was measured by filling the glass beaker up to brim with the help of a measuring cylinder. The root volume reading was recorded in $\mathrm{cm}^{3}$.

\section{Leaf to stem ratio}

The total dry weight of the stem and leaves was calculated and the ratio between the total leaf dry weight and the total stem dry weight was worked out. 


\section{Root to shoot ratio}

After recording the root volume those are sundried and later oven dried to record the total dry weight of the roots and the ratio between the total root to shoot dry weight was worked out.

\section{Yield per plant}

The yield per plant is calculated by averaging the yield of five plants.

\section{Stover yield per plant}

The total dry matter of the above ground part of five plants is averaged and the Stover yield per plant was worked out.

\section{Statistical Analysis}

The data collected from the experiment on various aspects of growth, yield and yield attributing characters of maize were arranged in appropriate tables according to the treatment and were subjected to statistical analysis in Randomized Block Design with the help of the statistical analysis tool (cropstat $7.2)$.

\section{Results and Discussion}

Leaf dry weight was recorded highest in Z695-1 (89.17) followed by Z630-3 and Z6381 . The percentage change of leaf dry weight with the tolerant check is $67 \%, 53 \%$ and $44 \%$ respectively. There is a percentage increase of $14 \%, 21 \%$, and $31 \%$ from 65 DAS to 90 DAS. A significant difference was observed among the germplasm lines in leaf dry weight. The reduced water potential in the leaves reduce the cell elongation and that consequently reduce the dry weight of the leaves. The leaf dry weight is directly related to the leaf area which indicates the higher leaf area at higher leaf weight. The germplasm with second higher leaf weight was the lowest yielder as the increased leaf area increase the water loss through surface which reduce the yield these findings are in accordance with Belaygue et al., 1996. The reduced leaf area is a survival strategy for the plan under drought conditions.

Stem dry weight was recorded highest in Z695-1 (110.59g) followed by Z638-1 (103.96g) and Z637-1 (101.06g). The percentage change of Stem dry weight with the tolerant check 900M Gold in these germplasm lines is $-15.84 \%,-20.89 \%$ and $23.09 \%$ respectively and a percentage increase of $79.68 \%, 8.34 \%$ and $74.87 \%$ from 45 DAS to 90 DAS was observed. There is a significant variation among the germplasm stem dry weight. The stem dry weight was observed to be increased significantly from 55 DAS to 65 DAS and a considerably less growth was observed at the critical stress period and the similar increase in shoot dry weight has been reported by Beiragi et al., 2011.

Root length and root volume of up-rooted plants of each germplasm line were recorded at two different times 65 DAS and 90 DAS and were presented in table 4 The maximum root volume was observed in Z695-2 $\left(382.52 \mathrm{~cm}^{3}\right)$ followed by Z630-2 and Z637-1 which was showing a percentage change of $7.20 \%, 5.45 \%$ and $-1.00 \%$ over the tolerant check $900 \mathrm{M}$ Gold.

There is a significant reduction in the root volume of four germplasm lines from 65 DAS to 90 DAS which show lower yields compared to the other germplasm lines. Root volume was observed to be increased from 65 DAS to 90 DAS. The highest root volume was recorded in the germplasm line Z695-2 $\left(383 \mathrm{~cm}^{3}\right)$ followed by Z630-2 $\left(376 \mathrm{~cm}^{3}\right)$ and Z637-1 $\left(353 \mathrm{~cm}^{3}\right)$. The drought tolerant germplasm lines are having more increase in root volume (Souza et al., 2016). The 
germplasm lines which show much increase in the root volume were observed to be higher in yield Z638-2 from $250 \mathrm{ml}$ to $309 \mathrm{ml}$ yielded $79.1 \mathrm{~g} /$ plant.

Root length was observed to be maximum in Z638-2 $(35.53 \mathrm{~cm})$ followed by Z638-1 and Z637-1 line. The root length recorded at 65 DAS showed an increase of $29.19 \%, 39.97 \%$ and $4.11 \%$ respectively and the length recorded at 90DAS showed an increase of $12.91 \%, 9.00 \%$ and $6.71 \%$ with the tolerant check. A significant difference was observed in all the germplasm lines. Root size and development is a crucial parameter in most selection program for drought resistance. Data indicated that increase in water stress caused a significant decrease in root length. Maximum root length $(33 \mathrm{~cm})$ recorded in Z630-4 followed by Z637-1 $(32 \mathrm{~cm}$ ) and Z630-3 (30 $\mathrm{cm})$ whereas minimum root length $(20 \mathrm{~cm})$ recorded in Z638-3. This results indicated adjustments in the root system which allows the plant to enter a static mode till the environment becomes favorable again (Fraser et al., 1990).

Root dry weight was recorded highest in Z637-2 (105.00) followed by Z630-2 and Z630-4. The percentage change of Root dry weight with the tolerant check is $23.53 \%$, $11.76 \%$ and $5.88 \%$ respectively. There is a percentage increase of $88.58,81.04$ and 116.24 from 45 DAS to 90 DAS. There is a significant variation among the germplasm Root dry weight. But the root and the leaf dry matter was also observed to be decreased with the stress and similar reductions in dry matter accumulation with the increase in the water stress has been reported by Cakir 2004.

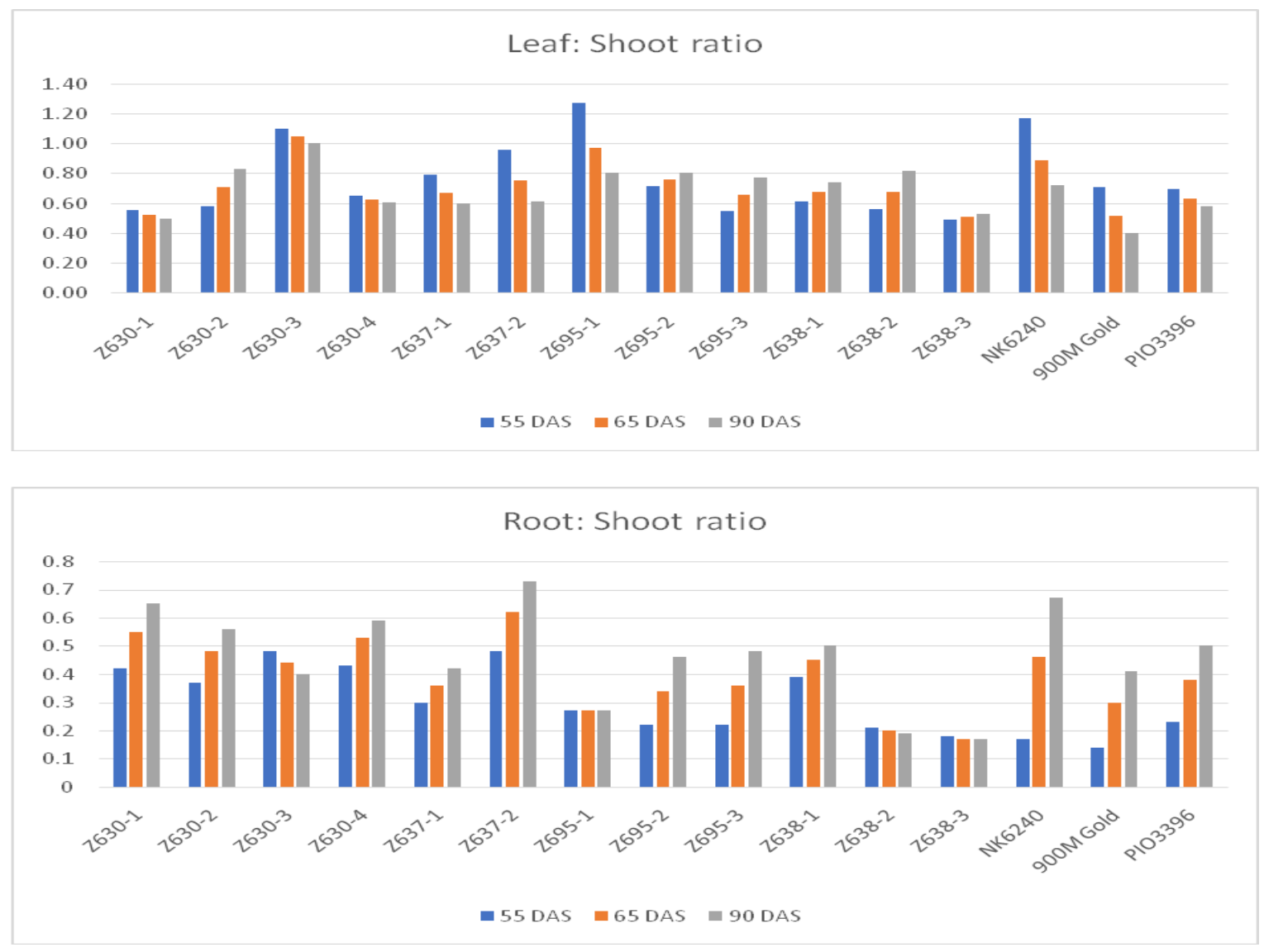

Fig.1 Effect of moisture deficit stress on Leaf to stem ratio in maize hybrid germplasm lines 
Fig.2 Effect of moisture deficit stress on Root to stem ratio in maize hybrid germplasm lines
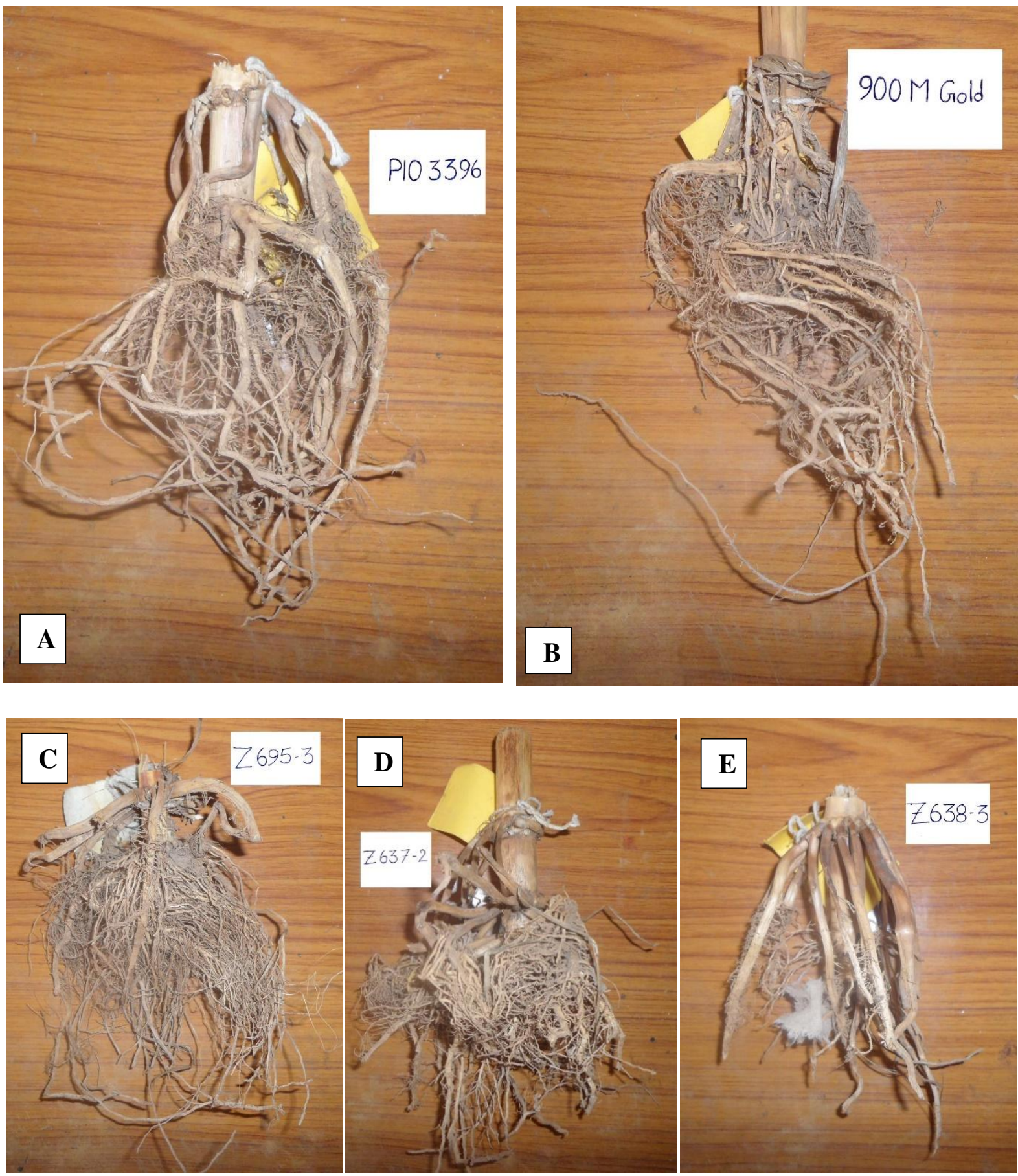

\section{Plate Description}

The above given plates are the root images at 65 DAS Plate (A) The check hybrid PIO 3396

(B) Check hybrid 900 M Gold (C) Tolerant germplasm line Z695-3 (D) Tolerant Germplasm line Z637-2 (E) Susceptible germplasm line Z638-2. 
Table.1 Effect of moisture deficit stress on Leaf dry weight (g/plant) in maize Hybrid germplasm lines

\begin{tabular}{|c|c|c|c|}
\hline Parameter & \multicolumn{3}{|c|}{ Leaf dry weight (g) } \\
\hline Treatment & 55 DAS & 65 DAS & 90 DAS \\
\hline Z630-1 & 37.67 & 39.67 & 41.67 \\
\hline Z630-2 & 51.67 & 64.17 & 76.67 \\
\hline Z630-3 & 67.67 & 74.67 & 81.67 \\
\hline Z630-4 & 38.33 & 48.33 & 58.33 \\
\hline Z637-1 & 45.83 & 53.33 & 60.83 \\
\hline Z637-2 & 58.17 & 56.67 & 55.17 \\
\hline Z695-1 & 78.17 & 83.67 & 89.17 \\
\hline Z695-2 & 58.33 & 63.33 & 68.33 \\
\hline Z695-3 & 56.67 & 66.67 & 76.67 \\
\hline Z638-1 & 58.83 & 67.83 & 76.83 \\
\hline Z638-2 & 62.5 & 68 & 73.5 \\
\hline Z638-3 & 43.67 & 42.67 & 41.67 \\
\hline NK6240 & 51.67 & 52.17 & 52.67 \\
\hline 900M Gold & 53.33 & 53.33 & 53.33 \\
\hline PIO3396 & 52.83 & 52.83 & 52.83 \\
\hline SE(m) \pm & 1.16 & 1.16 & 1.16 \\
\hline CD(0.05) & 2.87 & 2.87 & 2.87 \\
\hline CV (\%) & 3.69 & 3.39 & 3.14 \\
\hline
\end{tabular}

Table.2 Effect of moisture deficit stress on Stem dry weight (g/plant) in maize hybrid germplasm lines

\begin{tabular}{|c|c|c|c|}
\hline Parameter & \multicolumn{3}{|c|}{ Stem dry weight (g) } \\
\hline Treatment & 55 DAS & 65 DAS & 90 DAS \\
\hline Z630-1 & 67.80 & 75.57 & 83.34 \\
\hline Z630-2 & 88.65 & 90.55 & 92.46 \\
\hline Z630-3 & 61.45 & 71.37 & 81.29 \\
\hline Z630-4 & 58.82 & 77.27 & 95.73 \\
\hline Z637-1 & 57.79 & 79.42 & 101.06 \\
\hline Z637-2 & 60.51 & 75.39 & 90.28 \\
\hline Z695-1 & 61.55 & 86.07 & 110.59 \\
\hline Z695-2 & 81.76 & 83.38 & 85.01 \\
\hline Z695-3 & 103.59 & 101.17 & 98.75 \\
\hline Z638-1 & 95.95 & 99.95 & 103.96 \\
\hline Z638-2 & 111.53 & 100.77 & 90.00 \\
\hline Z638-3 & 88.44 & 83.55 & 78.65 \\
\hline NK6240 & 44.22 & 58.73 & 73.23 \\
\hline 900M Gold & 74.92 & 103.16 & 90.85 \\
\hline PIO3396 & 75.63 & 83.24 & 7.55 \\
\hline SE(m) \pm & 5.65 & 4.79 & 18.71 \\
\hline CD(0.05) & 14.01 & 11.87 & 13.94 \\
\hline CV $(\%)$ & 12.97 & 9.80 & \\
\hline
\end{tabular}


Table.3 Effect of moisture deficit stress on Root dry weight (g/plant) in maize Hybrid germplasm lines

\begin{tabular}{|c|c|c|c|}
\hline Parameter & \multicolumn{3}{|c|}{ Root dry weight (g) } \\
\hline Treatment & 55 DAS & 65 DAS & 90 DAS \\
\hline Z630-1 & 44.00 & 64.50 & 85.00 \\
\hline Z630-2 & 52.48 & 73.74 & 95.00 \\
\hline Z630-3 & 62.50 & 64.25 & 66.00 \\
\hline Z630-4 & 41.62 & 65.81 & 90.00 \\
\hline Z637-1 & 31.30 & 47.82 & 64.33 \\
\hline Z637-2 & 55.68 & 80.34 & 105.00 \\
\hline Z695-1 & 37.00 & 45.00 & 53.00 \\
\hline Z695-2 & 30.25 & 50.13 & 70.00 \\
\hline Z695-3 & 35.00 & 60.00 & 85.00 \\
\hline Z638-1 & 60.45 & 75.22 & 90.00 \\
\hline Z638-2 & 37.00 & 33.75 & 30.50 \\
\hline Z638-3 & 23.61 & 21.80 & 20.00 \\
\hline NK6240 & 16.25 & 50.63 & 85.00 \\
\hline 900M Gold & 29.25 & 52.13 & 75.00 \\
\hline PIO3396 & 17.50 & 46.25 & 75.00 \\
\hline SE(m) \pm & 3.66 & 7.27 & 15.00 \\
\hline CD(0.05) & 9.08 & 18.01 & 37.19 \\
\hline CV (\%) & 16.59 & 22.71 & 35.80 \\
\hline
\end{tabular}

Table.4 Effect of moisture deficit stress on Root length $(\mathrm{cm})$ and Root volume $\left(\mathrm{cm}^{3}\right)$ in maize hybrid germplasm lines

\begin{tabular}{|c|c|c|c|c|}
\hline Parameter & \multicolumn{2}{|c|}{ Root length $(\mathbf{c m})$} & \multicolumn{2}{c|}{ Root volume $\left(\mathbf{c m}^{\mathbf{3}}\right)$} \\
\hline Treatment & 65 DAS & 90 DAS & 65 DAS & 90 DAS \\
\hline Z630-1 & 24.50 & 26.06 & 24.50 & 26.06 \\
\hline $\mathbf{Z 6 3 0 - 2}$ & 22.20 & 26.00 & 22.20 & 26.00 \\
\hline $\mathbf{Z 6 3 0 - 3}$ & 30.00 & 22.23 & 30.00 & 22.23 \\
\hline $\mathbf{Z 6 3 0 - 4}$ & 33.00 & 24.03 & 33.00 & 24.03 \\
\hline $\mathbf{Z 6 3 7 - 1}$ & 32.25 & 33.58 & 32.25 & 33.58 \\
\hline $\mathbf{Z 6 3 7 - 2}$ & 20.25 & 29.48 & 20.25 & 29.48 \\
\hline $\mathbf{Z 6 9 5 - 1}$ & 29.00 & 23.94 & 29.00 & 23.94 \\
\hline $\mathbf{Z 6 9 5 - 2}$ & 29.25 & 29.67 & 29.25 & 29.67 \\
\hline $\mathbf{Z 6 9 5 - 3}$ & 23.25 & 26.38 & 23.25 & 26.38 \\
\hline $\mathbf{Z 6 3 8 - 1}$ & 24.50 & 34.29 & 24.50 & 34.29 \\
\hline $\mathbf{Z 6 3 8 - 2}$ & 27.50 & 35.53 & 27.50 & 35.53 \\
\hline $\mathbf{Z 6 3 8 - 3}$ & 21.25 & 23.69 & 21.25 & 23.69 \\
\hline NK6240 & 25.15 & 31.46 & 25.15 & 31.46 \\
\hline $\mathbf{9 0 0 M ~ G o l d}$ & 22.75 & 28.13 & 22.75 & 28.13 \\
\hline PIO3396 & 27.50 & 29.20 & 27.50 & 29.20 \\
\hline SE(m) \pm & 1.04 & 0.94 & 1.04 & 0.94 \\
\hline CD(0.05) & 2.57 & 2.32 & 2.57 & 2.32 \\
\hline CV (\%) & 6.86 & 5.74 & 6.86 & 5.74 \\
\hline
\end{tabular}


Table.5 Effect of moisture deficit stress on Grain yield (g/plant) and Stover yield (g/plant) in maize hybrid germplasm lines

\begin{tabular}{|c|c|c|}
\hline Treatment & Grain yield (g/plant) & Stover yield (g/plant) \\
\hline Z630-1 & 73.6 & 102.1 \\
\hline $\mathbf{Z 6 3 0 - 2}$ & 62.7 & 128.2 \\
\hline $\mathbf{Z 6 3 0 - 3}$ & 57.0 & 150.6 \\
\hline $\mathbf{Z 6 3 0 - 4}$ & 58.2 & 110.0 \\
\hline $\mathbf{Z 6 3 7 - 1}$ & 71.8 & 107.9 \\
\hline $\mathbf{Z 6 3 7 - 2}$ & 73.9 & 127.9 \\
\hline $\mathbf{Z 6 9 5 - 1}$ & 67.3 & 141.5 \\
\hline $\mathbf{Z 6 9 5 - 2}$ & 68.2 & 174.2 \\
\hline $\mathbf{Z 6 9 5 - 3}$ & 80.3 & 108.2 \\
\hline $\mathbf{Z 6 3 8 - 1}$ & 71.2 & 138.5 \\
\hline $\mathbf{Z 6 3 8 - 2}$ & 79.1 & 110.3 \\
\hline $\mathbf{Z 6 3 8 - 3}$ & 67.3 & 112.1 \\
\hline NK6240 & 67.0 & 108.5 \\
\hline $\mathbf{9 0 0 M}$ Gold & 70.6 & 120.6 \\
\hline PIO3396 & 76.4 & 129.7 \\
\hline SE(m) $\mathbf{\pm}$ & 10.2 & 24.27 \\
\hline $\mathbf{C D}(\mathbf{0 . 0 5})$ & 21.6 & 28.01 \\
\hline $\mathbf{C V}(\mathbf{\%})$ & 16.59 & 22.71 \\
\hline
\end{tabular}

The results obtained from the figure 1 show a regular pattern of increase in leaf: shoot ratio in some lines and decreasing trend in other line from 55 DAS to 90 DAS. Leaf to shoot ratio of the germplasm lines indicated that the terminal steep increase in leaf to shoot ratio in Z630-2 resulted in decreased yield in other germplasm lines where there is a considerable decrease in leaf dry weight given sustainable yields. In the other germplasm lines where the increase in leaf shoot ratio the yield also increased due to the much more accumulation of photosynthates etc.

The figure 2 depicted that the water stress significantly affected the root: shoot ratio. The root: shoot ratio was observed to be increased from 55 DAS to 90 DAS in all the germplasm lines. The highest root: shoot ratio was recorded in Z637-2 (0.48; 55DAS, 0.62; 65 DAS and 0.7390 DAS) followed by Z6301 (0.65) and Z630-4 (0.59). Root: soot ratio is observed to be more at 90 DAS. On an average the plants with higher root: shoot ratio were observed to show higher yields. Root: shoot ratio of plants increases under drought stress because roots are less sensitive than shoots to growth inhibition by low water potentials ( $\mathrm{Wu}$ and Cosgrove, 2000). The water stress imposition in maize hybrid germplasm lines reduced yield by 2 to 3 times than the normal conditions. There is a significant decrease in the leaf shoot and root dry matter due to the moisture deficit stress. There is less reduction in the stover yield as the moisture stress is induced during the reproductive growth phase. In case of the moisture stress tolerant germplasm lines when compared to a susceptible one the Stover yield, and grain yield per plant was observed to be more as reported by Khan et al., (2013), Abdelmula et al., 2007, Monneveux et al., 2008, Hussain et al., 2009, Akbar et al., 2009). 
From the obtained results of the experiment it is known that Root: shoot ratio, Root volume, Root length, Root dry weight can be used for the selection and characterization of the drought tolerant genotypes. The root architecture and spread studies are also very important and accurate studies for the characterization of drought resistant genotypes.

\section{Acknowledgement}

I would like to thank our university (Orissa University of Agriculture and Technology) for providing the facilities to successfully complete the research with all the cooperation needed. I cordially thank my Major Advisor Dr. Rajendra Kumar Panda who have given me the support both morally and academically. I cordially thank my present Guide Dr. G. Ramarao PS RRU Crop Physiology, RARS, Lam, ANGRAU, Guntur for encouraging me to do research and providing facilities for the proper functioning.

\section{References}

Abdelmula AA, and Sabiel SAI. 2007 "Genotypic and differential responses of growth and yield of some maize (Zea mays L.) Genotypes to drought stress." In Proceedings of the Tropical (Tropntag 2007) German Conference (Utilization of diversity in land): 9-11.

Akbar M, Saleem M, Ashraf MY, Hussin, M, Azhar FM and Ahmad R. 2009.Combining ability study for physiological and grain yield traits in maize at two temperature regimes. Pak. J. Bot. 41: 1817-1829.

Aslam, M., Maqbool, M.A. and Cengiz, R., 2015. Drought stress in maize (Zea mays L.): effects, resistance mechanisms, global achievements and biological strategies for improvement. Springer.
Beiragi MA, Ebrahimi M, Mostafavi K, Golbashy M and Khorasani SK 2011. A study of morphological basis of corn (Zea mays L.) yield under drought stress condition using correlation and path coefficient analysis. Journal of Cereals and Oilseeds, 2(2): 32-37.

Belaygue, C., Wery, J., Cowan, A. and Tardieu, F., 1996. Contribution of leaf expansion, rate of leaf appearance, and stolon branching to growth of plant leaf area under water deficit in white clover. Crop Science, 36(5), pp.1240-1246.

Cahn, M.D., Zobel, R.W. and Bouldin, D.R., 1989. Relationship between root elongation rate and diameter and duration of growth of lateral roots of maize. Plant and Soil, 119(2), pp.271279.

Cakir, R., 2004. Effect of water stress at different development stages on vegetative and reproductive growth of corn. Field Crops Research, 89(1), pp.116.

Du Plessis, J., 2003. Maize production (pp. 138). Pretoria, South Africa: Department of Agriculture.

Fraser, T.E., Silk, W.K. and Rost, T.L., 1990. Effects of low water potential on cortical cell length in growing regions of maize roots. Plant Physiology, 93(2), pp. 648-651.

Hajibabaee, M., Azizi, F. and Zargari, K., 2012. Effect of drought stress on some morphological, physiological and agronomic traits in various foliage corn hybrids. Am Eurasian J Agric Environ Sci, 12(7), pp.890-896.

Hussain I, Ahsan M, Saleem M and Ahmed A. 2009. Gene action studies for agronomic traits in maize under normal and water stress conditions. Pak. J. Agri. Sci. 46: 61-66.

Khan S, Inayat UA, and Mohammad SB 2013. Performance of maize varieties under irrigated conditions of dera ismail 
khan. Gomal University Journal of Research 29(2).

Monneveux P, Sanchez C, Tiessen A 2008. Future progress in drought tolerance in maize needs new secondary traits and cross combinations. The Journal of Agricultural Science, 146(3): 287-300.

Navara, J., Jesko, T. and Duchoslav, S., 1994. Participation of seminal roots in water uptake by the maize root system. Biologia. Ser. A. (Slovakia).

Nejad, T.S., A. Bakhshande, S.B. Nasab and K. Payande, 2010. Effect of drought stress on corn root growth. Report
Opinion, 2: 47-52

Souza, T.C.D., Magalhães, P.C., Castro, E.M.D., Duarte, V.P. and Lavinsky, A.O., 2016. Corn root morphoanatomy at different development stages and yield under water stress. Pesquisa Agropecuária Brasileira, 51(4), pp.330339.

Wu, Y. and Cosgrove, D.J., 2000. Adaptation of roots to low water potentials by changes in cell wall extensibility and cell wall proteins. Journal of Experimental Botany, 51(350), pp. 1543-1553.

\section{How to cite this article:}

Vadlamudi Dinesh Rahul, Rajendra Kumar Panda, Devraj Lenka and Rout G. R. 2019. A Study on the Root Characters of Maize Hybrid Germplasm Lines under Moisture Deficit Stress. Int.J.Curr.Microbiol.App.Sci. 8(08): 2836-2845. doi: https://doi.org/10.20546/ijcmas.2019.808.326 